ISSN 1980-5098 @) (i) DOI: http://dx.doi.org/10.5902/1980509831575

\title{
ESTOQUE DE CARBONO DE LATOSSOLOS EM SISTEMAS DE MANEJO NATURAL E ALTERADO
}

\section{LATOSOLS (OXISOLS) CARBON STORAGE IN NATURAL AND ALTERED MANAGEMENTS}

\author{
Ludmila de Freitas ${ }^{1}$ Ivanildo Amorim de Oliveira ${ }^{2}$ José Carlos Casagrande ${ }^{3}$ Laércio Santos Silva $^{4}$ \\ Milton César Costa Campos ${ }^{5}$
}

\section{RESUMO}

A conversão da condição natural do solo para a agricultura, em destaque para a monocultura de cana-deaçúcar impõe alterações nos atributos do solo. O objetivo do trabalho foi avaliar a variação do estoque de carbono de Latossolos com mata nativa, cana-de-açúcar e área reflorestada adjacentes, no município de Guariba - SP. Em cada área, foram coletadas, aleatoriamente, quatro amostras (compostas por quinze pontos), nas camadas de 0,0-0,10 e de 0,10-0,20 m. Foram avaliados os atributos densidade do solo, porosidade total, granulometria, teor de matéria orgânica, carbono orgânico total e estoque de carbono total no solo, de cada amostra nas duas profundidades estudadas. Os dados foram submetidos à análise de variância, correlação linear e análises multivariadas. Os resultados indicam que os teores de carbono são maiores nas camadas superficiais nas três áreas, decrescendo em profundidade. O solo da área de mata nativa apresenta o maior estoque de carbono, com $20,65 \mathrm{Mg} \mathrm{ha}^{-1}$, seguido pelo reflorestamento e cultivo de cana-de-açúcar, com 15,93 e 13,71 Mg ha ${ }^{-1}$, respectivamente, na profundidade de 0,0-0,10 m e 17,71 $\mathrm{Mg} \mathrm{ha}^{-1}$, seguido pelo reflorestamento e cultivo de cana-de-açúcar, com 14,86 e 12,06 $\mathrm{Mg} \mathrm{ha}^{-1}$, respectivamente, na profundidade de 0,10-0,20 m. Foi possível verificar tendo como referência a mata nativa, a perda de carbono no solo, sendo a área reflorestada e cultivada com cana-de-açúcar, na ordem de 22,9 e 33,6 \%, na profundidade de 0,0-0,10 m e de 31,9 e 16,1\% nas áreas reflorestada e cultivada com cana-de-açúcar na profundidade de 0,10-0,20 m, respectivamente. Assim, conclui-se que intervenção humana através de práticas agropecuárias reduz o estoque de carbono no solo a patamares inferiores ao encontrado em condições de mata nativa. Palavras-chave: cultivo de cana-de-açúcar; quantificação de carbono; reflorestamento; vegetação nativa.

\begin{abstract}
The natural condition conversion of the soil to agriculture, highlighting to the sugarcane monoculture, imposes changes in the soil attributes. This work aimed to evaluate the variation of the carbon storage of Oxisols under native forest, sugarcane, and adjacent reforested area, in Guariba, SP state. In each area, four samples (composed of fifteen points) were randomly collected, at 0.0-0.10 and 0.10-0.20 m layers. We evaluated soil density, total porosity, grain size, organic matter content, total organic carbon, and total soil carbon storage of each sample, at $0.0-0.10$ and $0.10-0.20 \mathrm{~m}$. Data were submitted to analysis of variance, linear correlation, and multivariate analyzes. The results indicate that the carbon content is higher in the

1 Bióloga, Dra ${ }^{\text {. }}$, Professora de Ensino Básico, Técnico e Tecnológico do Instituto Federal do Pará, Antônio Fulgêncio da Silva, s/n, Bairro Parque Universitário, CEP 68800-000, Breves (PA), Brasil. ludmila.freitas@ifpa.edu.br

2 2. Engenheiro Agrônomo, Dr., Professor de Ensino Básico, Técnico e Tecnológico do Instituto Federal do Pará, Antônio Fulgêncio da Silva, s/n, Bairro Parque Universitário, CEP 68800-000, Breves (PA), Brasil. ivanildo. oliveira@ifpa.edu.br

3 Engenheiro Agrônomo, Dr., Professor Associado da Universidade Federal de São Carlos, Rod. Anhanguera,Km 174, CEP 13601-490, Araras (SP), Brasil. bighouse@cca.ufscar.br

4 Engenheiro Agrônomo, MSc., Doutorando do Programa de Pós-Graduação em Ciência do Solo, Universidade Estadual Paulista, Via de Acesso Professor Paulo Donato Castellane s/n, CEP 14884-900, Jaboticabal (SP), Brasil. laerciosantos18@gmail.com

5 Engenheiro Agrônomo, Dr., Professor Adjunto do Instituto de Educação, Agricultura e Ambiente da Universidade Federal da Amazônia, Rua 29 de Agosto, 786, Bairro Divino Pranto, CEP 69800-000, Humaitá (AM), Brasil. mcesarsolos@gmail.com
\end{abstract}

Recebido para publicação em 5/10/2014 e aceito em 9/01/2017

Ci. Fl., v. 28, n. 1, jan.- mar., 2018 
superficial layers in all three areas, decreasing in depth. The soil of the native forest area has the highest carbon storage, $20.65 \mathrm{Mg} \mathrm{ha}^{-1}$, followed by reforestation and sugarcane cultivation areas, 15.93 and 13.71 $\mathrm{Mg} \mathrm{ha}^{-1}$ respectively at $0.0-0.10 \mathrm{~m}$, and $17.71 \mathrm{Mg} \mathrm{ha}^{-1}$, followed by reforestation and sugarcane cultivation areas, 14.86 and $12.06 \mathrm{Mg} \mathrm{ha}^{-1}$ respectively at $0.10-0.20 \mathrm{~m}$. It was possible to verify, comparing to the native forest, the loss of carbon in the soil, losses of 22.9 and $33.6 \%$ in the reforested and cultivated with sugar cane areas, at $0.0-0,10 \mathrm{~m}$, and 31.9 and $16.1 \%$ in the reforested and cultivated with sugarcane areas at $0.10-0.20 \mathrm{~m}$, respectively. Thus, we may conclude that the human intervention through agricultural practices reduces the carbon storage in the soil at lower levels than the ones found in native forest conditions.

Keywords: sugarcane growth; carbon quantification; reforestation; native vegetation.

\section{INTRODUÇÃO}

A implantação de atividades agrícolas e pecuárias estão modificando a cobertura vegetal original de grande parte do território brasileiro. Ecossistemas naturais vêm perdendo suas características cedendo lugar para essas atividades. O processo de substituição de áreas nativas por áreas de culturas anuais, como a canade-açúcar tem se intensificado nos últimos anos, e tem-se como consequência, a aceleração dos processos de degradação do solo, quando da não utilização de práticas de manejo adequado.

O solo é um recurso responsável pela produtividade agropecuária e pela manutenção da qualidade do meio ambiente (SHARMA et al., 2005). No entanto, quando manejados inadequadamente, o carbono orgânico pode ser mineralizado e transferido para a atmosfera na forma de $\mathrm{CO}_{2}$. Contudo, sob condições adequadas de manejo, o sistema pode sequestrar $\mathrm{C}$ da atmosfera, sendo esta uma importante estratégia regional e global para compensar as emissões de $\mathrm{CO}_{2}$ provenientes do uso de combustíveis fósseis e mitigar as mudanças climáticas (CERRI et al. 2006). Segundo Canellas et al. (2003) e Dias et al. (2007), os sistemas agrícolas monoculturais tradicionais são mais instáveis e provocam reduções nos estoques de carbono de várias frações orgânicas do solo. Em seu trabalho, Rosa et al. (2003) encontraram um declínio no conteúdo de carbono do solo em torno de 20 a $50 \%$, variando com a profundidade, quando os ecossistemas naturais foram substituídos por sistemas de cultivos. De acordo com Galdos et al. (2009), em seu estudo, observaram que a conversão de uma área de reserva natural em área cultivada com cana-de-açúcar, mesmo com diversidades de tratos culturais causou redução dos teores de carbono total, carbono da biomassa microbiana e carbono orgânico particulado, principalmente na camada superficial do solo.

Em solos sob vegetação natural, o balanço entre as adições e perdas de carbono leva a um estado de equilíbrio dinâmico, no qual praticamente não existe variação no teor de carbono orgânico com o tempo (BAYER; MIELNICZUK, 1999). No entanto, na conversão de áreas com vegetação natural em agrícolas e florestais, verifica-se, de maneira geral, nas regiões tropicais, uma rápida perda de carbono orgânico do solo, em decorrência da combinação entre calor e umidade, que facilita a decomposição, e o constante revolvimento do solo contribui para acelerar a oxidação do carbono orgânico (CASTRO FILHO et al., 1991). Segundo Denardin et al. (2014), estudos do ciclo do carbono apresentam grande interesse devido à sua implicação nas mudanças climáticas, por influência da alteração das emissões dos gases de efeito estufa (GEEs). As práticas agrícolas e as mudanças do uso do solo devido ao desmatamento são as principais fontes de emissão dos GEEs. Além disso, o ciclo do carbono está muito associado aos ecossistemas tropicais que emitem e/ou absorvem o $\mathrm{CO}_{2}$ do ar. Dessa forma, a alteração de ecossistemas naturais, decorrente de distúrbios naturais e atividades agrícolas, trarão mudanças nos fluxos de carbono para a atmosfera, em níveis que irão variar com a intensidade do distúrbio (PAIVA et al., 2011).

Neste sentido, o estoque de carbono de um solo sob vegetação natural representa o balanço dinâmico entre a adição de material vegetal morto e a perda pela decomposição ou mineralização (SCHOLES et al., 1997) ou seja, se encontram em um estado de equilíbrio dinâmico, no qual há um balanço entre as entradas através da deposição da serapilheira e a perda de carbono do solo na forma de $\mathrm{CO}_{2}$, oriundo da respiração dos organismos vivos do solo. Segundo Cambardella et al. (1994), este estoque, bem como outros atributos do solo, determina o impacto das atividades agrícolas ao ambiente, que podem variar com tempo e também no espaço, razão pelo qual o conhecimento da sua variabilidade dos atributos do solo é importante, sobretudo para o ajuste fino das práticas de manejo e avaliação dos efeitos da agricultura sobre a qualidade ambiental. Diversos trabalhos mostram redução nos estoques de C do solo após a conversão de 
áreas nativas para cultivos agrícolas (BAYER; MIELNICZUK, 1999; RESCK et al., 2000). De acordo com Dias (2010), uma das principais razões da diminuição dos estoques de carbono no solo após a implantação de espécies cultivadas é que a biomassa produzida nos sistemas agrícolas (sementes, frutos e parte da palhada) é removida e exportada para comercialização ou utilização em outro lugar.

Como o processo de substituição de áreas de mata nativa por áreas com diferentes manejos tem se intensificado nos últimos anos, como consequência uma aceleração dos processos de degradação destas áreas, quando da não utilização de práticas de manejo adequado. Dentro desse contexto, os diferentes sistemas de manejo do solo podem afetar diretamente o seu teor de carbono orgânico, e este, por sua vez, pode ser usado como um indicador de qualidade dos solos. Desta forma, o presente trabalho teve por objetivo avaliar a variação na concentração e no estoque de carbono orgânico sob diferentes manejos em Latossolos em relação à mata nativa.

\section{MATERIAL E MÉTODOS}

As áreas estudadas localizam-se no nordeste do Estado de São Paulo, no município de Guariba - SP, com altitude de $600 \mathrm{~m}$ e o clima é o Cwa, segundo a classificação de Köppen, do tipo mesotérmico com inverno seco, precipitação pluvial média de $1.400 \mathrm{~mm}$ e chuvas concentradas no período de novembro a fevereiro. O solo foi classificado como Latossolo Vermelho Distrófico típico, textura franco-argiloarenoso, segundo critérios da Embrapa (2013), situado em relevo plano. As áreas estão inseridas no Planalto Ocidental Paulista, próximo ao limite das Cuestas Basálticas (INSTITUTO DE PESQUISAS TECNOLÓGICAS DO ESTADO DE SÃO PAULO, 1981a), no divisor litoestratigráfico arenito basáltico (INSTITUTO DE PESQUISAS TECNOLÓGICAS DO ESTADO DE SÃO PAULO, 1981b). O material de origem está relacionado à transição Basalto do Grupo São Bento Formação Serra Geral, Depósito Colúvio-Eluvionar e Depósito Aluvionar (INSTITUTO DE PESQUISAS TECNOLÓGICAS DO ESTADO DE SÃO PAULO, 1981b).

O experimento foi realizado em três áreas contíguas com os seguintes manejos: 1) área com mata em condição natural (AM), cuja localização geográfica é $21^{\circ} 27^{\prime} 44^{\prime \prime} \mathrm{S}$ e $48^{\circ} 19^{\prime} 29^{\prime} \mathrm{W}$, caracterizada como Floresta Estacional Semidecidual Tropical Subcaducifólia, sem intervenção humana nem histórico de cultivo agrícola com cerca de 60 anos e com 18 ha de extensão; 2) área com cultivo de cana-de-açúcar (AC), com coordenadas de $21^{\circ} 27^{\prime} 39^{\prime \prime}$ S e 48 $19^{\prime} 71^{\prime}$ 'W, cultivada há 60 anos, com extensão de 50 ha; o preparo do solo para o plantio foi realizado com arado de discos e grade pesada; em seguida, foi realizada subsolagem; a adubação utilizada foi somente torta de filtro, não havendo aplicação de qualquer outro tipo de fertilizante;

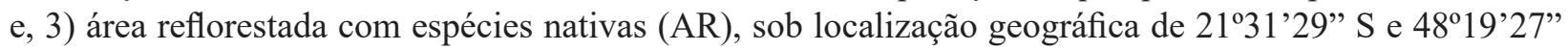
$\mathrm{W}$, implantada há oito anos, sendo que anteriormente foi explorada com a monocultura de cana-de-açúcar por 40 anos e nesta área foram introduzidas algumas espécies nativas pelos próprios trabalhadores locais, sem base científica (Figura 1).

As áreas foram subdivididas em quatro subáreas, sendo coletada uma amostra composta de 15 pontos amostrais aleatórios em cada subárea, na camada de 0,0-0,10 m e 0,10-0,20 m totalizando oito amostras por área, correspondendo a 4 repetições por profundidade em cada área.

Os indicadores físicos quantificados foram determinados em amostras indeformadas na forma de anel volumétrico, coletadas nas minitrincheiras, nas profundidades de 0,0-0,10 m e de 0,10-0,20 m. No laboratório, esses anéis foram saturados por meio da elevação gradual de uma lâmina de água até atingir cerca de $2 / 3$ da altura do anel, para determinação da porosidade total $(\mathrm{Pt})$ obtida pela diferença entre a massa do solo saturado e a massa do solo seco em estufa a $105^{\circ} \mathrm{C}$ durante $24 \mathrm{~h}$ (EMBRAPA, 1997). A microporosidade do solo foi determinada pelo método da mesa de tensão, segundo metodologia da Embrapa (2011). Pela diferença entre a porosidade total e a microporosidade, obteve-se a macroporosidade. A densidade do solo (Ds) foi calculada pela relação entre a massa seca a $105^{\circ} \mathrm{C}$ durante $24 \mathrm{~h}$ da amostra de solo do cilindro volumétrico e o volume do mesmo cilindro (EMBRAPA, 2011). A análise granulométrica foi determinada pelo método da pipeta, após dispersão da amostra com $\mathrm{NaOH} 1,0 \mathrm{~mol} \mathrm{~L}^{-1}$ e agitação rápida (6.000 rpm), por 15 minutos (EMBRAPA, 2011). 


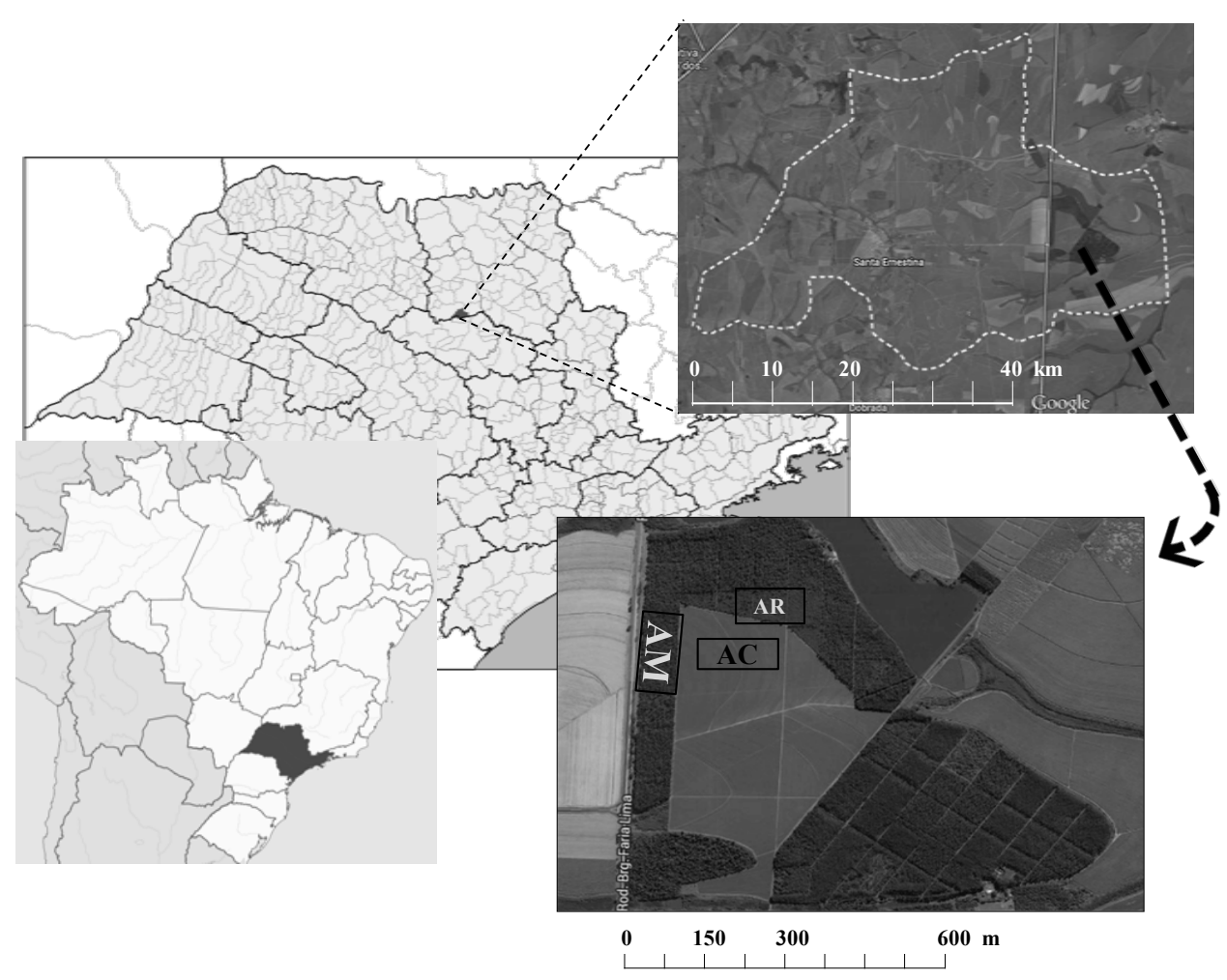

FIGURA 1: Localização das áreas: $\mathrm{AC}$ = área cultivada com cana de açúcar; $\mathrm{AR}$ = Área com reflorestamento; $\mathrm{AM}=$ área cultivada com mata nativa.

FIGURE 1: Location of areas: $\mathrm{AC}=$ Area cultivated with sugar cane; $\mathrm{AR}=$ Area with reforestation; $\mathrm{AM}=\mathrm{Area}$ with Native Forest.

O carbono total foi determinado pelo método de Walkley-Black modificado por Yeomans e Bremner (1988), a matéria orgânica por sua vez, estimada com base no carbono orgânico. A transformação dos valores de carbono orgânico para matéria orgânica foi realizada pela relação:

$$
\mathrm{MO}=1,724 \times \mathrm{CO}
$$

Em que: $\mathrm{MO}=$ matéria orgânica do solo; $\mathrm{CO}=$ teor de $\mathrm{C}$ orgânico total na profundidade amostrada $\left(\mathrm{g} \mathrm{kg-1}{ }^{1}\right)$.

O estoque de carbono (Est C) calculado pela expressão (VELDKAMP, 1994):

$$
\text { Est } \mathrm{C}=(\mathrm{CO} \times \mathrm{Ds} \mathrm{x}) / 10
$$

Em que: Est $\mathrm{C}=$ estoque de $\mathrm{C}$ orgânico em determinada profundidade $\left(\mathrm{Mg} \mathrm{ha}^{-1}\right) ; \mathrm{CO}=$ teor de $\mathrm{C}$ orgânico total na profundidade amostrada $\left(\mathrm{g} \mathrm{kg}^{-1}\right)$; Ds $=$ densidade do solo da profundidade $\left(\mathrm{kg} \mathrm{dm}^{-3}\right) ; \mathrm{e}=$ espessura da camada considerada $(\mathrm{cm})$.

Os resultados foram analisados por meio de análise de variância e as médias comparadas pelo teste Tukey a $5 \%$ de probabilidade utilizando-se o Statistical Analysis System (SAS). Efetuou-se também um estudo de correlação entre os valores de teor de matéria orgânica e os valores de porosidade total e densidade do solo, com fornecimento do coeficiente de correlação significativo a $5 \%$ de probabilidade pelo teste determinando-se o grau de maior coeficiente de determinação $\left(\mathrm{R}^{2}\right)$. Para tal procedimento, foi utilizado o aplicativo computacional Excel (Office 2007).

O efeito do manejo do solo e sua interação sobre cada variável original e fator extraído foram testados pelo General Linear Model (GLM), utilizado como análise de variância multivariada, sendo 
que esse procedimento analisou as três áreas com os atributos estudados. O objetivo desta análise foi o de verificar se os valores de $\mathrm{F}$ formados pelas médias das variáveis analisadas conjuntamente diferiram quando os ambientes foram contrastados entre si. Em caso afirmativo indica que os manejos são diferentes, analisando todos os atributos em conjunto.

A fim de comparar os perfis das diferentes áreas utilizando todas as variáveis conjuntamente, foi realizada uma análise complementar que é a análise discriminante, uma matriz de classificação de dados. A partir desta análise foi possível definir o quão distintas são as áreas estudadas, sendo estas representadas em um gráfico, no qual é possível verificar a separação entre elas. Os eixos deste gráfico representam as variáveis canônicas, que são novas variáveis multivariadas criadas a partir do conjunto original de variáveis. Todas as análises estatísticas foram processadas com auxílio do programa estatístico Statistica 7.0.

\section{RESULTADOS E DISCUSSÕES}

Devido às pequenas variações de relevo, a distribuição granulométrica nos diferentes usos foi semelhantes para as três áreas estudadas (Tabela 1). Em todas as áreas, observou-se dominância da fração areia nas camadas avaliadas, fato justificável pela natureza aluvial dos sedimentos que constituem o material de origem (BRASIL, 1978). No entanto, a argila apresenta altos valores, sendo esta condição decorrente principalmente, devido às áreas estarem próximas ao limite das Cuestas Basálticas, no divisor litoestratigráfico arenito basáltico, conforme encontrado por Meireles et al. (2012).

Nas três áreas avaliadas verificou-se menor densidade do solo (Ds) na camada superficial, (Tabela 1). Segundo Denardin et al. (2014), esse resultado pode ser explicado por ser a camada de maior interação com a fonte de resíduos, ou a camada de maior aporte de resíduos orgânicos. Ainda assim, não se verificou diferença significativa entre as diferentes profundidades em nenhum dos manejos (Tabela 1).

Na mata nativa, a variação da Ds apresentou o padrão que normalmente se verifica para a maioria dos solos, que, segundo Cavenage et al. (1999), em condições naturais, aumenta em profundidade, em função do menor teor de matéria orgânica (MO) e do peso das camadas de solo sobrejacentes, corroborando os resultados encontrados por Denardin et al. (2014).

A Ds foi maior nas áreas antropizadas em comparação com a mata nativa em ambas as profundidades analisadas. Estes resultados estão de acordo com os obtidos por Islam e Weil (2000), Araújo et al. (2004) e Viana et al. (2011). Em seu trabalho, Silva e Ribeiro (1992), Portugal et al. (2010), Freitas et al. (2012) obtiveram resultados similares, comparando solo cultivado com cana-de-açúcar e sob mata nativa. A maior Ds nos solos cultivados está relacionada com a compactação pelo tráfego de máquinas e implementos agrícolas (CAVENAGE et al., 1999; HAMZA; ANDERSON, 2005; FREITAS et al., 2011). Para Steinbeiss et al. (2009), a menor densidade do solo nas áreas com mata nativa deve-se aos elevados teores de carbono orgânico e de intensa atividade biológica (fauna e raízes).

A porosidade total na mata nativa apresentou os maiores valores, de acordo com a Tabela 1. Tais valores foram significativamente menores no solo cultivado em comparação com os do solo sob mata nativa. Resultados similares, em solo cultivado com cana-de-açúcar, foram obtidos por Silva e Ribeiro (1992) e Freitas et al. (2011). A drástica redução da porosidade total nos solos cultivados decorre do aumento da compactação do solo, que é evidenciada pelo aumento da densidade do solo (SILVA et al., 2008; ANDRADE et al., 2009; FREITAS et al., 2011; CUNHA et al., 2012).

As mudanças nos sistemas estudados influenciaram a concentração de matéria orgânica no solo (Tabela 1). Os valores de matéria orgânica mostraram-se superiores nas camadas superficiais, o que já havia sido observado por Araújo et al. (2004) e Freitas (2011), diferenciando-se das camadas subsuperficiais. Os valores de MO foram estatisticamente maiores na mata, nas duas profundidades avaliadas, indicando que a retirada da mata e a utilização agrícola reduziram os teores de $\mathrm{C}$ orgânico no solo. Devido ao revolvimento dos solos sob cultivo, a aeração é maior sendo a mineralização de MO favorecida, o que explica os resultados observados e também um maior acúmulo de restos vegetais, proporcionando o acúmulo de MO no solo (RANDO, 1981). Esses resultados também estão de acordo com Portugal et al. (2010), segundo os quais há um declínio no estoque de MO após a conversão de florestas nativas em sistemas agrícolas. Segundo esses autores, essa redução pode ser atribuída ao aumento da erosão do solo, aos processos mais acelerados de mineralização da MO do solo e a menores quantidades de aportes orgânicos em sistemas manejados

Ci. Fl., v. 28, n. 1, jan.- mar., 2018 
comparativamente às florestas nativas, o que está ocorrendo em maior intensidade nas áreas com o cultivo de cana-de-açúcar.

TABELA 1: Atributos do solo analisados em diferentes profundidades avaliados em função dos manejos.

TABLE 1: Soil attributes analyzed at different depths evaluated according to managements.

\begin{tabular}{|c|c|c|c|c|c|c|c|}
\hline \multirow{3}{*}{ Variáveis } & & \multicolumn{6}{|c|}{ Manejos } \\
\hline & \multirow[b]{2}{*}{ Unidade } & \multicolumn{3}{|c|}{-----Profundidade 0,0 - 0,10 m----- } & \multicolumn{3}{|c|}{----Profundidade $0,10-0,20 \mathrm{~m}$----- } \\
\hline & & $\mathrm{AC}$ & $\mathrm{AR}$ & $\mathrm{AM}$ & $\mathrm{AC}$ & $\mathrm{AR}$ & $\mathrm{AM}$ \\
\hline Argila & $\%$ & $30,25 b$ & $29,25 \mathrm{a}$ & $31,0 \mathrm{a}$ & $29,25 \mathrm{a}$ & $31,25 \mathrm{a}$ & $31,25 \mathrm{a}$ \\
\hline Areia & $\%$ & $65,45 \mathrm{a}$ & $63,95 \mathrm{a}$ & $64,1 \mathrm{a}$ & $66,15 \mathrm{a}$ & $62,05 \mathrm{a}$ & $64,45 \mathrm{a}$ \\
\hline Silte & $\%$ & $4,3 \mathrm{c}$ & $6,80 \mathrm{c}$ & $4,9 \mathrm{c}$ & $4,6 \mathrm{c}$ & $6,7 \mathrm{c}$ & $4,3 \mathrm{c}$ \\
\hline Ds & $\mathrm{g} / \mathrm{cm}^{-3}$ & $1,62 \mathrm{a}$ & $1,42 b$ & $1,19 \mathrm{c}$ & $1,73 \mathrm{a}$ & $1,48 \mathrm{~b}$ & $1,24 \mathrm{c}$ \\
\hline $\mathrm{Pt}$ & $\%$ & $39,45 c$ & $47,12 b$ & $55,58 \mathrm{a}$ & $37,62 c$ & $45,86 \mathrm{~b}$ & $55,27 \mathrm{a}$ \\
\hline MO & $\mathrm{g} / \mathrm{dm}^{3}$ & $13,82 \mathrm{c}$ & $18,81 b$ & $29,05 \mathrm{a}$ & $12,05 \mathrm{c}$ & $17,35 b$ & $24,85 \mathrm{a}$ \\
\hline COT & $\mathrm{g} \mathrm{kg}^{-1}$ & $7,98 \mathrm{c}$ & $10,88 b$ & $16,82 \mathrm{a}$ & $6,97 \mathrm{~b}$ & $10,08 \mathrm{ab}$ & $14,35 \mathrm{a}$ \\
\hline EST C & $\mathrm{Mg} \mathrm{ha}^{-1}$ & $13,71 \mathrm{~b}$ & $15,93 \mathrm{~b}$ & $20,65 a$ & $12,06 \mathrm{~b}$ & $14,86 \mathrm{ab}$ & $17,71 \mathrm{a}$ \\
\hline
\end{tabular}

Em que: médias seguidas por letras minúsculas iguais na linha não diferem entre si pelo teste de Tukey ao nível de $1 \%$ de significância. $\mathrm{AC}$ = área cultivada com cana de açúcar; $\mathrm{AR}=$ Área reflorestada; $\mathrm{AM}=$ Área com mata nativa (referencial); $\mathrm{Pt}=$ Porosidade total do solo; $\mathrm{Ds}=$ Densidade do solo; $\mathrm{MO}=$ Matéria orgânica do solo; $\mathrm{COT}=$ Carbono orgânico do solo; EST C = Estoque de carbono do solo.

$\mathrm{Na}$ Figura 2 fica evidente o efeito da MO nas propriedades físicas do solo. Observa-se correlação positiva entre o teor de MO e a Pt (Figura 2A) e correlação negativa entre a MO e a Ds (Figura 2B), conforme encontrado por Calonego et al. (2012). Dessa forma, o aumento do teor de MO em qualquer que seja o manejo é uma maneira de melhorar as características físicas do solo. Em seu trabalho, Calonego e Rosolem (2008) verificaram aumento do teor de MO com o cultivo por três anos consecutivos de Crotalaria juncea como planta de cobertura entre os meses de outubro e novembro, antecedendo cultivo de soja em sistema de semeadura direta (SSD), quando comparado com o solo mantido em pousio nessa época. Calonego et al. (2012), trabalhando com solos sob diferentes manejos, encontraram correlação entre a MO e a densidade do solo, com o $\mathrm{R}^{2}=0,64$ e entre a $\mathrm{MO}$ e a porosidade total de $\mathrm{R}^{2}=0,44$, esses autores, também encontram maiores valores de MO nos manejos que mantiveram e/ou aumentaram o teor de matéria orgânica do solo.

Os teores de carbono orgânico total no solo (COT) nos diferentes sistemas estudados apresentaram comportamento semelhante aos valores de MO, sendo os maiores teores em superfície na profundidade de 0,00-0,10 m e decréscimo com o aumento da profundidade (Tabela 1), corroborando os resultados encontrados por Neves et al. (2004), Sisti et al. (2004), Siqueira Neto et al. (2009), Vasconcelos et al. (2010), Calonego et al. (2012) e Barros et al. (2013). Os maiores teores de carbono no solo, para a camada de $0,00-0,10 \mathrm{~m}(\mathrm{p}<0,05)$, foram encontrados para a mata nativa $\left(16,28 \mathrm{~g} \mathrm{~kg}^{-1}\right)$, área reflorestada $(10,88 \mathrm{~g}$ $\left.\mathrm{kg}^{-1}\right)$, em relação à área cultivada com cana-de-açúcar $\left(7,98 \mathrm{~g} \mathrm{~kg}^{-1}\right)$. $\mathrm{O}$ mesmo ocorreu na profundidade de 0,10-0,20 m (14,35 $\mathrm{g} \mathrm{kg}^{-1}$ para mata nativa, $10,01 \mathrm{~g} \mathrm{~kg}^{-1}$ para área reflorestada e $6,97 \mathrm{~g} \mathrm{~kg}^{-1}$ para a área com cana-de-açúcar). Este fato, segundo Barros et al. (2013), justifica-se pelo maior aporte de material orgânico na superfície do solo, proveniente da queda de folhas, galhos e da casca de árvores, na mata nativa, somando-se aos resíduos das colheitas nas áreas cultivadas, formando a manta orgânica e a maior densidade de raízes finas, de acordo com Gatto et al. (2010) que estimaram o estoque de carbono no solo com plantações de eucalipto na região centro-leste do Estado de Minas Gerais. 

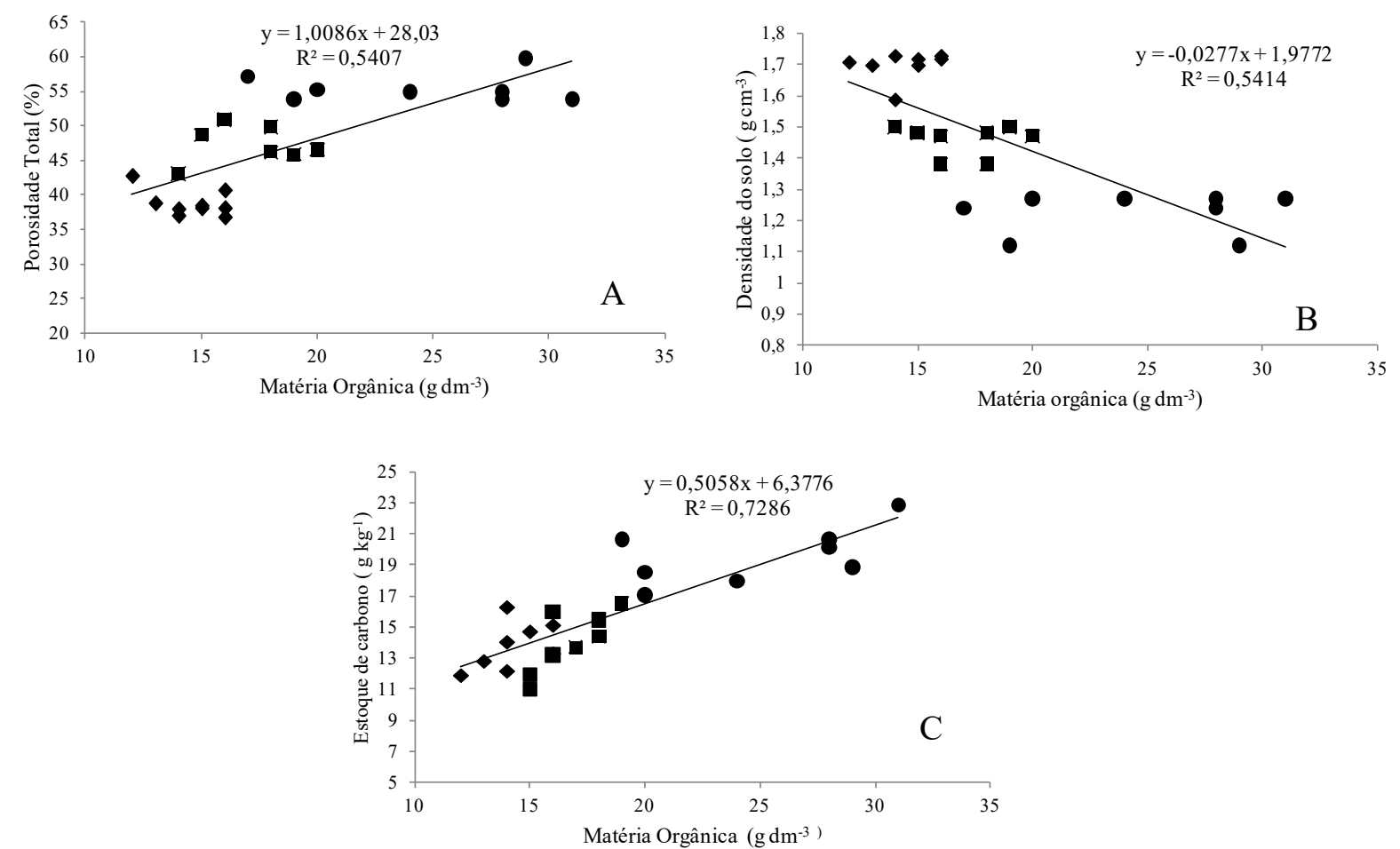

FIGURA 2: Correlação entre o teor de matéria orgânica do solo e a porosidade total (A), teor de matéria orgânica do solo e densidade do solo (B) e teor de matéria orgânica do solo com estoque de carbono (C).

FIGURE 2: Correlation between the content of soil organic matter and total porosity (A), soil bulk density (B) and carbon stock $(\mathrm{C})$.

No ambiente natural, nas duas profundidades avaliadas, os teores mais elevados de carbono no solo são decorrentes do maior aporte de resíduos vegetais e não perturbação do sistema. Na área reflorestada, devido a este ambiente apresentar ausência de revolvimento do solo há aproximadamente dez anos e apresentar resíduos e cobertura do solo com grande aporte de material vegetal, tais fatores favorecem a agregação que protegem da mineralização e promove aumento da MOS (SIQUEIRA NETO et al., 2009), enquanto a área cultivada com cana-de-açúcar, por se tratar de uma área manejada e a ação antrópica que provoca compactação no solo, devido ao revolvimento do solo e uso de implementos agrícolas apresentam menores teores de carbono no solo. Segundo Stevenson (1982), a redução do aporte de CO no solo não se deve unicamente à redução da quantidade de resíduos adicionados, mas também, ao aumento da atividade microbiana, causado por melhores condições de aeração, temperaturas mais elevadas e alternância mais frequente de umedecimento e secagem do solo, pelo uso contínuo de implementos, pela sucessão contínua, pelas queimadas, e pelas perdas causadas pela própria erosão. Na profundidade de $0,10-0,20 \mathrm{~m}$ não houve interação significativa entre os ambientes estudados.

Nos dados apresentados na Tabela 1, fica evidente o efeito dos diferentes manejos do solo utilizados nas diferentes áreas sobre o estoque atual de C no solo. Para Costa et al. (2008) e Alves et al. (2008), em sistemas estáveis como a mata nativa, a estabilidade dos estoques de $\mathrm{C}$ ocorre devido à adição contínua de resíduos orgânicos ao solo, sendo que o limite deste acúmulo é dependente da quantidade de resíduos produzidos e da ação microbiana, que tendem a ser estáveis, sofrendo alterações em situações específicas (secas, geadas, entre outras), mas cujos efeitos, pela periodicidade e/ou intensidade, normalmente, não se manifestam nos níveis de $\mathrm{C}$ estocados no solo

No presente trabalho, o solo da área de mata nativa foi considerado referência, sendo o estoque atual estimado em 20,6 $\mathrm{Mg} \mathrm{ha}^{-1}$ e $17,71 \mathrm{Mg} \mathrm{ha}^{-1}$ na profundidade de 0,0-0,10 m e 0,10-0,20 m respectivamente considerando o teor de $\mathrm{C}$ e a densidade de cada camada avaliada. Verifica-se redução de $4,72 \mathrm{Mg}^{-1}$ no solo em AR e 6,94 Mg ha- ${ }^{-1} \mathrm{AC}$ em relação à AM na profundidade de 0,0-0,10 m e de 2,85 $\mathrm{Mg} \mathrm{ha}^{-1}$ no solo em AR e 5,65 $\mathrm{Mg} \mathrm{ha}^{-1} \mathrm{em} \mathrm{AC}$ em relação à AM na profundidade de 0,10-0,20 m. Estes dados evidenciam os efeitos negativos que o manejo convencional pode promover na qualidade do solo, além de outros 
prejuízos ambientais, econômicos e sociais (DIEKOW et al., 2005). Por outro lado, não se pode afirmar que estes valores equivalem à perda real de $\mathrm{C}$ nas áreas, mas sim à condição atual de estoque de $\mathrm{C}$, pois na área cultivada com cana-de-açúcar e área reflorestada, diferentes manejos foram adotados após a retirada da mata nativa.

Chaves e Farias (2008) em área de cultivo de cana-de-açúcar dos Tabuleiros Costeiros Paraibanos, constataram estoque de carbono de $33,82 \mathrm{Mg} \mathrm{ha}^{-1}$ na camada superficial (0-30 $\mathrm{cm}$ de profundidade), enquanto nos demais horizontes $(30-63 \mathrm{~cm} ; 63-100 \mathrm{~cm})$ os estoques foram de 26,37 e 21,21 $\mathrm{Mg} \mathrm{ha}^{-1}$, respectivamente. Cavalcante et al. (2006) avaliando estoques de carbono para diferentes condições de uso e manejo, observaram que para todas as condições observadas, as quantidades e estoque de carbono foram menores do que o da área nativa tomada como referência. Este fato foi atribuído à maior atividade microbiana proporcionada pelo não revolvimento do solo. Quando o solo é submetido ao cultivo convencional, o revolvimento contribui para acelerar a oxidação do carbono orgânico.

Para melhor entender as relações entre os três ambientes analisados, é possível verificar, contrastando os ambientes estudados por meio da Tabela 2, que os maiores valores de F são encontrados quando a área cultivada com cana-de-açúcar é comparada com a mata nativa.

TABELA 2: Resultado da Análise Multivariada (MANOVA) contrastando as áreas estudadas com todas as variáveis em conjunto.

TABLE 2: Results of Multivariate Analysis (MANOVA) contrasting the studied areas with all of the variables together.

\begin{tabular}{lcc}
\hline & Profundidade $0,0-0,10 \mathrm{~m}$ & Profundidade $0,10-0,20 \mathrm{~m}$ \\
\hline Manejos & MANOVA $-\mathrm{F}$ & MANOVA $-\mathrm{F}$ \\
\hline AC x AR & $421,58^{* * *}$ & $413,79^{* * *}$ \\
AC x AM & $689,21^{* * *}$ & $542,36^{* * *}$ \\
AM x AR & $503,39^{* * *}$ & $478,42^{* * *}$ \\
\hline
\end{tabular}

Em que: = valores são significativos para $p<0.001$

Nota-se que a área reflorestada está mais próxima do ambiente cultivado que o da mata nativa, apesar do alto aporte de resíduos orgânicos (verificou-se considerável acúmulo de serapilheira), o solo apresentou valores intermediários na maioria de seus atributos avaliados. Pode-se inferir que, apesar dos dez anos de reflorestamento, e não revolvimento do solo, este período não foi suficiente para recuperação das características originais do solo (solo de mata nativa). É importante considerar que a área esteve sob cultivo de cana-de-açúcar por mais de 40 anos. Outra explicação para este resultado seria o solo da área cultivada ser o mais revolvido devido às práticas culturais adotadas, ao uso intensivo de implementos agrícolas que afetam diretamente os atributos analisados. Essas diferenças de agrupamento são resultado, portanto, das diferenças dos atributos observadas, possibilitando uma análise mais generalizada da qualidade das áreas estudadas. As áreas de cana-de-açúcar e reflorestada, apesar de serem estatisticamente diferentes, possuem características mais semelhantes, devido aos seus menores valores de F. Uma explicação provável para este resultado deve-se provavelmente ao cultivo da cana-de-açúcar promover depreciação da MO em função do preparo intensivo do solo e de uso de fertilizantes.

$\mathrm{Na}$ análise discriminante foram consideradas as duas primeiras raízes canônicas: A Can 1 e Can 2 (raiz canônica 1 e raiz canônica 2, respectivamente), pois estes conseguem reter cumulativamente a quantidade suficiente da informação total contida no conjunto das variáveis originais, para cada ambiente, em ambas as profundidades analisadas. De maneira geral observou-se que as duas primeiras canônicas armazenaram 84,60 \% da variância original dos atributos do solo na profundidade de 0,0-0,10 m (Figura $3 \mathrm{~A}$ ) e de $84,78 \%$ na profundidade de 0,10-0,20 m (Figura 3B). Segundos Sena et al. (2002), para estudos de solos, valores acima de $70 \%$ da variância original acumulada são considerados valores aceitáveis, validando assim as informações do trabalho em questão.

A análise discriminante mostrou que levando em conta todos os atributos analisados houve clara distinção entre ambientes (Figuras 3A, B), em que a área cultivada com cana-de-açúcar é encontrada no primeiro quadrante, a área de mata nativa no segundo quadrante e a área reflorestada entre o terceiro $\mathrm{e}$ 
quarto quadrante. De acordo com Toledo et al. (2009), após esta etapa, a análise multivariada pode ser aplicada na seleção de variáveis relevantes na caracterização e no planejamento de uso sustentável de ambientes naturais.

Com base nos resultados em ambas as profundidades, constatou-se a formação de três grupos diferentes, um grupo é referente ao conjunto de dados que contemplam a área de mata nativa, outro grupo engloba a área reflorestada e um terceiro grupo é formado pela área cultivada com cana-de-açúcar (Figura 3). Estes resultados vêm confirmar que o uso da análise multivariada pode servir para agrupar indivíduos com características semelhantes e estudar suas correlações (VALLADARES et al., 2008), sendo, neste caso específico, bastante úteis para o estudo de solos submetidos a diferentes manejos.

A variação dos atributos do solo na vegetação nativa é menor quando se compara com solos de usos agrícolas, e por isso a vegetação nativa é referencial para avaliação de solos incorporados a sistemas agrícolas. Nessa comparação, é possível observar, que a área reflorestada está entre os dois ambientes quanto aos
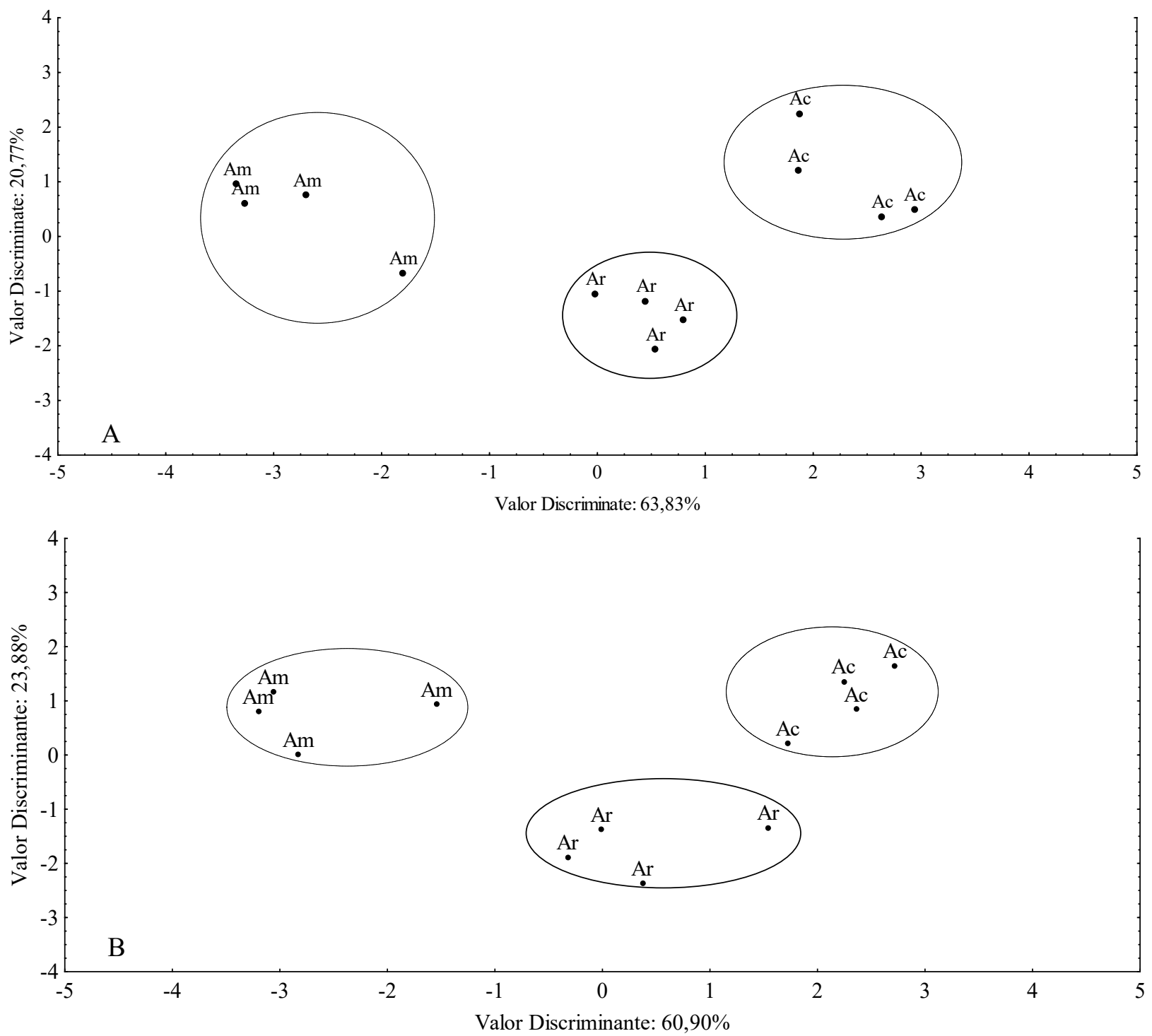

FIGURA 3: Agrupamento das áreas pela Análise Discriminante Canônica 1 e 2. Ac = área cultivada com cana de açúcar; $\mathrm{Ar}=$ Área reflorestada; $\mathrm{Am}=$ Área com mata nativa (referencial). A = profundidade de 0,0-0,10 $\mathrm{m} ; \mathrm{B}=$ profundidade de 0,10 a $0,20 \mathrm{~m}$.

FIGURE 3: Principal Components Analysis for the soil attributes AC = area cultivated with sugar cane; $A R=A r e a$ reforested; $\mathrm{Am}=$ Area of native forest (reference). The $=$ depth of $0.0-0.10 \mathrm{~m} ; \mathrm{B}=$ depth of 0.10 to 0.20 m. 
atributos estudados, demonstrando a recuperação da qualidade do solo na área em reflorestamento, apesar desta apresentar características mais próximas do ambiente cultivado.

Essa separação dos pontos da mata com as demais é um indicador que a área cultivada intensivamente com cana-de-açúcar tem seus atributos afetados acentuadamente, fazendo com que o mesmo se torne diferente do solo originalmente coberto por floresta. Segundo Spera et al. (2004), à medida que essas áreas vão sendo incorporadas ao processo produtivo os atributos físicos do solo sofrem alterações. As diferenças são devidas às variações de fertilidade natural da mata e aquelas decorrentes de diferentes níveis de adubação da cana.

Nota-se que independentemente da análise realizada neste trabalho, os solos cultivados com canade-açúcar e a área reflorestada apresentaram comportamento ou características aproximadas, quando considerado o conjunto das variáveis em estudo, conforme observado por Freitas et al. (2014). No entanto, com relação à área cultivada com cana-de-açúcar, o uso do solo provocou alteração nos atributos estudados, o que pode levar à degradação destes com o tempo, como pode ser observado na Figura 2, pela separação entre os ambientes.

Os resultados obtidos demonstram, claramente, que o manejo inadequado do solo, ou a alteração da cobertura vegetal, podem levar a grandes perdas do carbono estocado em um curto espaço de tempo. Estes resultados demonstraram que a mata nativa possui um potencial de estoque de carbono mais elevado do que o sistema de cana-de-açúcar, indicando a relevância da manutenção destas áreas de mata para compensar as emissões advindas dos sistemas de produção de cana-de-açúcar.

\section{CONCLUSÕES}

O solo da área de mata nativa apresenta o maior estoque de carbono, com 20,65 $\mathrm{Mg} \mathrm{ha}^{-1}$, seguido pelo reflorestamento e cultivo de cana-de-açúcar, com 15,93 e 13,71 $\mathrm{Mg} \mathrm{ha}^{-1}$, respectivamente, na profundidade de $0,0-0,10 \mathrm{~m}$ e $17,71 \mathrm{Mg} \mathrm{ha}^{-1}$, seguido pela área reflorestada e de cana-de-açúcar, com 14,86 e 12,06 Mg $\mathrm{ha}^{-1}$, respectivamente, na profundidade de $0,10-0,20 \mathrm{~m}$.

Tomando a área de mata nativa como referência, verificam-se perdas de carbono no solo das áreas reflorestada e cultivada com cana-de-açúcar, na ordem de 22,9 e 33,6 \%, respectivamente, na profundidade de $0,0-0,10 \mathrm{~m}$ e de 31,9 e $16,1 \%$ nas áreas reflorestada e cultivada com cana-de-açúcar, respectivamente na profundidade de $0,10-0,20 \mathrm{~m}$.

A intervenção humana através de práticas agropecuárias reduz o estoque de carbono no solo a patamares inferiores ao encontrado em condições de mata nativa.

\section{REFERÊNCIAS}

ALVES, B. J. R. et al. Dinâmica de carbono em solos sob pastagens. In: SANTOS, G. A. et al. (Ed.). Fundamentos da matéria orgânica do solo: ecossistemas tropicais e subtropicais. 2. ed. Porto Alegre: Metrópole, 2008. 654 p.

ANDRADE, R. S. et al. Culturas de cobertura e qualidade física de um Latossolo em plantio direto. Revista Brasileira de Engenharia Agrícola Ambiental, Campina Grande, v. 13, n. 4, p. 411-418, 2009. ARAÚJO, M. A. et al. Propriedades físicas de um Latossolo Vermelho distrófico cultivado e sob mata nativa. Revista Brasileira de Ciência do Solo, Viçosa, MG, v. 28, n. 2, p. 337-345, 2004.

BARROS, J. D. et al. Estoque de carbono e nitrogênio em sistemas de manejo do solo, nos tabuleiros costeiros paraibanos. Revista Caatinga, Mossoró, v. 26, n. 1, p. 35-42, 2013.

BAYER, C.; MIELNICZUK, J. Dinâmica e função da matéria orgânica. In: SANTOS, G. A.; CAMARGO, F. A. O. (Ed.). Fundamentos da matéria orgânica do solo: ecossistemas tropicais e subtropicais. Porto Alegre: Gênesis, 1999. p. 9-26.

BRASIL. Ministério das Minas e Energia. Projeto Radambrasil. Purus, Rio de Janeiro, v. 20, p. 56, 1978. CALONEGO, J. C. et al. Estoques de carbono e propriedades físicas de solos submetidos a diferentes sistemas de manejo. Revista Caatinga, Mossoró, v. 25, n. 2, p. 128-135, 2012.

CALONEGO, J. C.; ROSOLEM, C. A. Estabilidade de agregados do solo após manejo com rotações de culturas e escarificação. Revista Brasileira de Ciência do Solo, Viçosa, MG, v. 32, n. 4, p. 1399-1407, 
2008.

CAMBARDELLA, C. A. et al. Field-scale variability of soil properties in Central Iowa Soils. Soil Science Society of America Journal, Madison, v. 58, n. 4, p. 1501-1511, 1994.

CANELLAS, L. P. et al. Estoque e qualidade da matéria orgânica de um solo cultivado com cana-de-açúcar por longo tempo. Revista Brasileira de Ciência do Solo, Viçosa, MG, v. 31, n. 2, p. 331-340, 2007.

CASTRO FILHO, $\mathrm{C}$ et al. Tillage methods and soil and water conservation in southern Brazil. Soil Tillage, Amsterdam, v. 20, n.3, p. 271-283, 1991.

CAVALCANTE, F. S. et al. Estoque de carbono e nitrogênio do solo sob diferentes manejos. In: REUNIÃO BRASILEIRA DE MANEJO E CONSERVAÇÃO DO SOLO E DA ÁGUA, 16., 2006, Aracaju. Anais... Aracaju: SBCS, 2006. CD Rom.

CAVENAGE, A. et al. Alterações nas propriedades físicas de um Latossolo Vermelho-Escuro sob diferentes culturas. Revista Brasileira de Ciência do Solo, Viçosa, MG, v. 23, n. 4, p. 997-1003, 1999.

COSTA, F. S. et al. Estoque de carbono orgânico no solo e emissões de dióxido de carbono influenciadas por sistemas de manejo no Sul do Brasil. Revista Brasileira de Ciência do Solo, Viçosa, MG, v. 32, n. 1, p. 323-332, 2008.

CUNHA, Q. E. et al. Atributos físicos, químicos e biológicos de solo sob produção orgânica impactados por sistemas de cultivo. Revista Brasileira de Engenharia Agrícola e Ambiental, Campina Grande, v. 16, n. 1, p. 56-63, 2012.

DENARDIN, R. B. N. et al. Estoque de carbono no solo sob diferentes formações florestais, Chapecó - SC. Ciência Florestal, Santa Maria, v. 24, n. 1, p. 59-69, 2014.

DIAS, B. O. et al. Estoque de carbono e quantificação de substâncias húmicas em Latossolo submetido à aplicação contínua de lodo de esgoto. Revista Brasileira de Ciência do Solo, Viçosa, MG, v. 31, n. 4, p. 701-711, 2007.

DIAS, R. R. A. Modelagem dos estoques de carbono do solo sob diferentes coberturas na região do cerrado. 2010. 120 f. Dissertação (Mestrado em Ecologia) - Universidade de Brasília, Brasília, 2010.

DIEKOW, J. et al. Soil $\mathrm{C}$ and $\mathrm{N}$ stocks as affected by cropping systems and nitrogen fertilization in a southern Brazil Acrisol managed under no-tillage for 17 year. Soil and Tillage Research, Amsterdan, v. 81, n. 1, p. 87-95, 2005.

EMBRAPA. Centro Nacional de Pesquisa de Solos. Manual de métodos de análise de solo. Rio de Janeiro: Embrapa, 1997. 212 p.

EMBRAPA. Centro Nacional de Pesquisa de Solos. Sistema brasileiro de classificação de solos. 3. ed. Brasília: Embrapa, 2013. 353 p.

FREITAS, L. et al. Análises multivariadas de atributos físicos em Latossolo Vermelho submetidos a diferentes ambientes. Enciclopédia Biosfera, Goiânia, v. 8, n. 15, p. 126-139, 2012.

FREITAS, L. et al. Análises multivariadas de atributos químicos do solo para caracterização de ambientes. Revista Agro@mbiente On-line, Boa Vista, v. 8, n. 2, p. 155-164, 2014.

FREITAS, L. Influência de fragmentos florestais nativos sobre os parâmetros químicos, físicos e microbiológicos de solos cultivados com cana-de-açúcar. 2011. 112 f. Dissertação (Mestrado em Ciências Biológicas) - Universidade Estadual Paulista, Rio Claro, 2011.

FREITAS. L. et al. Atributos químicos e físicos de solo cultivado com cana-de-açúcar próximo a fragmento florestal nativo. Holos Environment, Rio Claro, v. 11, n. 2, p. 137-147, 2011.

GALDOS, M. V. et al. Simulation of soil carbon dynamics under sugarcane with the Century Model. Soil Science Society of America Journal, Madison, v. 73, n. 3, p. 802-811, 2009.

GATTO, A. et al. Estoque de carbono no solo e na biomassa em plantações de eucalipto. Revista Brasileira de Ciência do Solo, Viçosa, MG, v. 34, n. 5, p. 1069-1079, 2010.

HAMZA, M. A.; ANDERSON, W. K. Soil compaction in cropping systems: a review of the nature, causes and possible solutions. Soil Tillage Research, Amsterdam, v. 82, n. 2, p. 121-145, 2005.

INSTITUTO DE PESQUISAS TECNOLÓGICAS DO ESTADO DE SÃO PAULO. Mapa Geomorfológico do Estado de São Paulo. São Paulo: IPT, 1981a. v. 1. Escala 1:1.000.000.

INSTITUTO DE PESQUISAS TECNOLÓGICAS DO ESTADO DE SÃO PAULO. Mapa Geológico do Estado de São Paulo. São Paulo: IPT, 1981b. v. 1. Escala 1:500.000.

ISLAM, K. R.; WEIL, R. R. Soil quality indicator properties in mid-atlantic soils as influenced by 
conservation management. Journal of Soil and Water Conservation, Ankeny, v. 55, n. 1, p. 69-78, 2000. MEIRELES, H. T. et al. Relações solo-paisagem em topossequência de origem basáltica. Pesquisa Agropecuária Tropical, Goiânia, v. 42, n. 2, p. 129-136, 2012.

NEVES, C. M. N. et al. Estoque de Carbono em sistemas agrossilvopastoril, pastagem e eucalipto sob cultivo convencional na Região Noroeste do Estado de Minas Gerais. Ciência Agrotécnica, Lavras, v. 28, n. 5, p. 1038-1046, 2004.

PAIVA, A. O. et al. Estoque de carbono em cerrado sensu stricto do Distrito Federal. Revista Árvore, Viçosa, MG, v. 35, n. 3, p. 527-538, 2011.

PORTUGAL, A. F. et al. Propriedades físicas e químicas do solo em áreas com sistemas produtivos e mata na região da Zona da Mata mineira. Revista Brasileira de Ciência do Solo, Viçosa, MG, v. 34, n. 2, p. $575-585,2010$.

RANDO, E. M. Alterações nas características e propriedades físicas de um Latossolo Roxo distrófico, ocasionadas pelo cultivo convencional. 1981. 161 f. Dissertação (Mestrado em Ciência do solo) - Escola Superior de Agricultura de Lavras, Lavras, 1981.

ROSA, M. E. C. et al. Formas de carbono em Latossolo Vermelho eutroférrico sob plantio direto no sistema biogeográfico do cerrado. Revista Brasileira de Ciência do Solo, Viçosa, MG, v. 27, n. 5, p. 911-923, 2003.

SCHOLES, M. C. et al. Input control of organic matter dynamics. Geoderma, Amsterdam, v. 79, n. 1/4, p. 25-47, 1997.

SHARMA, K. L. et al. Longterm soil management effects on crop yields and soil quality in a dryland Alfisol. Soil \& Tillage Research, Amsterdam, v. 83, n. 2, p. 246-259, 2005.

SILVA, F. F. et al. Propriedades físicas de um Latossolo Vermelho cultivado no sistema plantio direto. Irriga, Botucatu, v. 13, n. 2, p. 191-204, 2008.

SILVA, M. S. L; RIBEIRO, M. R. Influência do cultivo contínuo da cana-de-açúcar em propriedades morfológicas e físicas de solos argilosos de tabuleiro no Estado de Alagoas. Revista Brasileira de Ciência do Solo, Viçosa, MG, v. 16, n. 3, p. 397-402, 1992.

SIQUEIRA NETO, M. et al. Carbono total e atributos químicos com diferentes usos do solo no cerrado. Acta Scientiarum Agronomy, Maringá, v. 31, n. 4, p. 709-717, 2009.

SISTI, C. P. J. et al. Change in carbon and nitrogen stocks in soil under 13 years of conventional or zero tillage in southern Brazil. Soil Tillage Research, Amsterdam, v. 76, n. 1, p. 39-58, 2004.

SPERA, S. T. et al. Efeitos de sistemas de produção de grãos envolvendo pastagens sob plantio direto nos atributos físicos de solo e na produtividade. Revista Brasileira de Ciência do Solo, Viçosa, MG, v. 28, n. 3, p. 533-542, 2004.

STEINBEISS, S. et al. Effectof biochar amendment on soil carbon balance and soil microbial activity. Soil Biology \& Biochemistry, Oxford, v. 41, n. 6, p. 1301-1310, 2009.

VASCONCELOS, R. F. B. et al. Estabilidade de agregados de um Latossolo Amarelo distrocoeso de tabuleiro costeiro sob diferentes aportes de resíduos orgânicos da cana-de-açúcar. Revista Brasileira de Ciência do Solo, Viçosa, MG, v. 34, n. 2, p. 309-316, 2010.

VELDKAMP E. Organic carbon turnover in three tropical soils under pasture after Deforestation. Soil Science Society of America Journal, Madison, v. 58, p. 175-180, 1994.

VIANA, E. T. et al. Atributos físicos e carbono orgânico em Latossolo Vermelho sob diferentes sistemas de uso e manejo. Revista Brasileira de Ciência do Solo, Viçosa, MG, v. 35, n.6, p. 2105-2114, 2011.

YEOMANS, J. C.; BREMNER, J. M. A rapid and precise method for routine determination of organic carbon in soil. Communication in Soil Science and Plant Analysis, New York, v. 19, n. 13, p. 1467-1476, 1988. 